\title{
MUSICOTERAPIA, DEFICIÊNCIA INTELECTUAL E MUSICALIZAÇÃO TERAPÊUTICA: UMA ENTREVISTA COM ANA SHEILA TANGARIFE
}

\author{
MUSIC THERAPY, INTELLECTUAL DISABILITY AND THERAPEUTIC \\ MUSICALIZATION: AN INTERVIEW WITH ANA SHEILA TANGARIFE
}

\begin{abstract}
Bruna Meneses ${ }^{1}$; Fernanda Santos ${ }^{2}$; Giovana Brizolla ${ }^{3}$; Livia Quintanilha ${ }^{4}$; Luiz Costa-Lima Neto ${ }^{5}$; Naurinei Costa ${ }^{6}$; Paulo Alexandre Monteiro ${ }^{7}$; Suzana de Alencar Freitas ${ }^{8}$; Vinicius Martins ${ }^{9}$
\end{abstract}

\begin{abstract}
Resumo - Entrevista com a musicoterapeuta Ana Sheila Tangarife, realizada remotamente em 23 de julho de 2020 pelo Grupo de Estudos Independente de Musicoterapia (GEIMT), formado em meio à pandemia da Covid-19, por alunos/as do curso de Pós-Graduação em Musicoterapia do Conservatório Brasileiro de Música (CBM/RJ). Após ser transcrito pelo GEIMT, este texto foi revisado pelos professores e musicoterapeutas Lia Rejane Mendes Barcellos, Rafael Lima dos Santos e pela entrevistada. Ana Sheila Tangarife formou-se no curso de Graduação em Musicoterapia do CBM/RJ em 1980 e é Especialista em Educação Musical e Mestre em Música pela mesma instituição. Acumula mais de 40 anos em experiências profissionais na área da Musicoterapia, foi coordenadora da Clínica Social Ronaldo Millecco e docente dos cursos de Graduação e Pós-Graduação em Musicoterapia no CBM/RJ, além de atuar no Instituto de Psicologia Clínica Educacional e Profissional (IPCEP) e na Sociedade Pestalozzi do Brasil (SPB/Brasil). Baseada em sua longa experiência profissional em instituições públicas e privadas, no atendimento de
\end{abstract}

\footnotetext{
${ }^{1}$ Bacharel em Serviço Social pela Universidade Estácio de Sá (UNESA), menesesbruna@gmail.com, http://lattes.cnpq.br/5074345277307446.

${ }^{2}$ Licenciada em Pedagogia e Especialista em Psicopedagogia pelo Centro Universitário Geraldo Di Biase (FERP), pedagoga.fernanda.santos@gmail.com, http://lattes.cnpq.br/9432095035745550.

3 Licenciada em Música pela Universidade Federal do Pampa (UNIPAMPA), giovanacox@gmail.com, http://lattes.cnpq.br/3894447637767746.

Licenciada em Música pela Faculdade Batista do Rio de Janeiro (FABAT), liviaquintanilha0@gmail.com, http://lattes.cnpq.br/6685307068437036.

${ }^{5}$ Doutor em Musicologia pela Universidade Federal do Estado do Rio de Janeiro (UNIRIO) e pósdoutor em História pela Universidade Federal Fluminense (UFF), costalimaneto.luiz@gmail.com, http://lattes.cnpq.br/8887112313026244.

Licenciado em Música pelo Conservatório Brasileiro de Música (CBM/CEU),

naurinei@gmail.com, http://lattes.cnpq.br/1554295244502684.
Bacharel em Turismo pela Universidade Federal do Paraná (UFPR), p.alexandre420@gmail.com, http://lattes.cnpq.br/1026956132673597.

Licenciada em Pedagogia pela Pontifícia Universidade Católica do Rio de Janeiro (PUC-RJ), suzana.freitas93@gmail.com, http://lattes.cnpq.br/1526683164251237.

${ }^{9}$ Licenciado em Música pelo Conservatório Brasileiro de Música (CBM/CEU) e Especialista em Educação Musical e Ensino de Artes pela Universidade Candido Mendes (UCAM), viniciusmartins_19@hotmail.com, http://lattes.cnpq.br/2104376119659477.
}

Revista Brasileira de Musicoterapia - Ano XXII n² 28 ANO 2020

MENESES, Bruna et al. Musicoterapia, deficiência intelectual e musicalização terapêutica: uma entrevista com Ana Sheila Tangarife

(p. $71-88)$ 


\section{RBMT}

Revista Brasileira

de Musicoterapia

pessoas com deficiência intelectual, Tangarife aborda tópicos importantes relacionados aos temas da Musicoterapia e deficiência intelectual, Musicalização Terapêutica, inclusão social e Educação Musical apresentando uma contribuição inédita para a área da Musicoterapia, em seus aspectos práticos e teóricos.

Palavras-chave: musicoterapia, deficiência intelectual, musicalização terapêutica, educação musical.

Abstract - Interview with music therapist Ana Sheila Tangarife, carried out remotely on July 23rd, 2020 by the Independent Music Therapy Study Group (GEIMT), formed amid the Covid-19 pandemic, by students of the Music Therapy Postgraduate Course from the Brazilian Music Conservatory (CBM / $\mathrm{RJ})$. After being transcribed by GEIMT, this text was revised by teachers and music therapists Lia Rejane Mendes Barcellos, Rafael Lima dos Santos and by the interviewee. Ana Sheila Tangarife has a BA in Music Therapy, is postgraduated in Music Education, and obtained her MA in Music from CBM / RJ. Tangarife has over 40 years of professional experience in the area of Music Therapy, was coordinator of the Social Clinic Ronaldo Millecco, and professor of the Undergraduate and Postgraduate Courses in Music Therapy at CBM / RJ. The interviewee worked at the Institute of Educational and Professional Clinical Psychology (IPCEP) and the Brazilian Pestalozzi Society (SPB / Brasil). Based on her long professional experience in public and private institutions, treating people with intellectual disabilities, Tangarife addresses important topics related to Music Therapy and Intellectual Disability, Therapeutic Musicalization, Social Inclusion, and Musical Education, offering an unprecedented contribution to the field of Music Therapy, presenting practical and theoretical reflections.

Keywords: music therapy, intellectual disability, therapeutic musicalization, music education. 
GEIMT - Em sua opinião, há diferenças entre Educação Musical e Musicoterapia quanto aos seus objetivos ou meios?

Ana Sheila - Creio que isso deve estar bem claro para vocês, que o professor Rafael ${ }^{10}$ deve ter falado bastante sobre isso. Entretanto, o que vale ressaltar aqui é que a Musicoterapia veio da Educação Musical, dos educadores musicais, que foram os primeiros pedagogos musicais, os quais considero os primeiros "musicoterapeutas" no passado. Dalcroze ${ }^{11}$ foi um deles, assim como Llongueras ${ }^{12}$ e outros vários que começaram a fazer trabalhos com cegos, com crianças com problemas os mais variados possíveis. Dalcroze foi um dos primeiros que começou a receber nas suas classes crianças com alguma disfunção, algum problema. Então, para mim, estes foram os primeiros "musicoterapeutas" da história. Nós estamos aqui e devemos a estas pessoas, pois naquela época a Musicoterapia ainda não existia como prática profissional. Devemos deixar muito claro o seguinte: utilizamos os recursos da Educação Musical no trabalho com as pessoas com deficiência intelectual, mas todas as formas que são utilizadas, assim como os métodos para musicalização, são adaptadas dentro das condições e possibilidades dos sujeitos. Neste sentido, tudo é muito adequado, nunca utilizamos a metodologiae os exercícios como são aplicados para as crianças sem deficiências. Tudo é muito simplificado, dependendo do nível de deficiência e limitações.

Eu já tive muitos alunos de Musicoterapia ao longo desses anos todos e é

\footnotetext{
${ }^{10}$ Rafael Lima dos Santos, musicoterapeuta Mestre em Psicologia PUC-RJ, é professor da disciplina de Musicoterapia e Deficiência Intelectual, do Curso de Pós-Graduação Lato Sensu Especialização em Musicoterapia do Conservatório Brasileiro de Música.

${ }^{11}$ Émile Jacques-Dalcroze (1865 - 1950) foi o criador de um sistema de ensino musical baseado no movimento corporal expressivo (Eurritmia). Por sua pedagogia musical, Dalcroze é considerado o precursor dos chamados métodos ativos de Educação Musical. Ver: Ermelinda A. Paz. Pedagogia musical no século XX: metodologias e tendências. Brasília: Editora Musimed, 2000, p. 10.

${ }_{12}$ Joan Llongueras i Badia (1880 - 1953) foi um compositor, educador musical e poeta, o qual criou, em 1912, o Instituto Catalão de Artes Rítmicas e Plásticas, introduzindo a metodologia dalcroziana na Catalunha/Espanha. Ver "Biografías y Vidas". Disponível em:

<https://www.biografiasyvidas.com/biografia///longueras.htm>. Acesso em: 03/10/2020.
}

Revista Brasileira de Musicoterapia - Ano XXII n² 28 ANO 2020

MENESES, Bruna et al. Musicoterapia, deficiência intelectual e musicalização terapêutica: uma entrevista com Ana Sheila Tangarife

(p. 71 - 88) 


\section{RBMT}

Revista Brasileira

de Musicoterapia

importante ressaltar que eles se sentiam ofendidíssimos quando chegavamàs instituições e ouviam: "Olha, chegou o professor de música". Hoje em dia isto não acontece mais porque já somos muitos musicoterapeutas, mas, há cerca de 25 anos, na cabeça das pessoas leigas, a musicoterapia era "aula de música". Eu dizia: "Mas não se preocupem com isso, batam nesta tecla, vocês são musicoterapeutas". O importante é que vocês tenham a consciência e a certeza de que são terapeutas. Não há demérito nenhum, você pode usar recursos da Educação Musical, mas você não é somente mais um professor demúsica, poderá até ser professor dentro do espectro da Musicalização Terapêutica, entendeu? Os métodos, objetivos e as deficiências dependem e diferenciam muito esses campos de atuação.

GEIMT - Um questionamento que surgiu durante uma das apresentações de trabalho foi que, segundo alguns autores, a diferença entre aEducação Musical e a Musicoterapia está justamente nos objetivos. Mas existem autores que propõem que a diferença entre as áreas está no meio, ou seja, no procedimento. Teria alguma diferença? Isso se confirma?

Ana Sheila - Sim, há diferença, pois quando falamos em Educação Musical estamos nos referindo ao trabalho com crianças que não têm nenhum tipo de deficiência, sem nada que as impeça de aprender a tocar um instrumento e a ler música, mas aqui nós estamos falando de pessoas com deficiência intelectual. Então, a questão da aprendizagem já não é um objetivo principal, pois eles não vão aprender a tocar música, não vão aprender a leituramusical. Tudo é adaptado para eles, entendeu? É isso que, em minha opinião, acontece. As áreas são completamente diferentes, são trabalhos diferentes com pessoas que podem ter uma formação como Educadores Musicais. Eu, particularmente, sempre sonhei que os alunos da graduação em Musicoterapia viessem da Educação Musical, pois seriam musicoterapeutas bem capacitados! Eles teriam toda essa gama, esse leque de possibilidades para trabalhar, que uma pessoa leiga, que não é educador musical, pode ter mais dificuldades em saber usar.

Revista Brasileira de Musicoterapia - Ano XXII n² 28 ANO 2020

MENESES, Bruna et al. Musicoterapia, deficiência intelectual e musicalização terapêutica: uma entrevista com Ana Sheila Tangarife

(p. $71-88)$ 


\section{RBMT}

Revista Brasileira

Para os objetivos da Musicoterapia não importa a questão do fazer e aprender música e da estética musical, mas é bom ressaltar uma coisa: a gente não persegue a estética desesperadamente e nem fica aguardando que ela apareça no setting. Agora, quando ela aparece é uma alegria, é um prazer e a gente tem que realmente incentivar. A questão da estética, para o professor de música, em comparação com o musicoterapeuta, é muito diferente. Por exemplo: para nós, musicoterapeutas, o autista que nunca se comunicou ou não quis falar, está no setting, porém ignora você, não emite som, mas um dia ele dá um grito! Esse grito para nós tem beleza porque quando ele dá esse grito, quando olha para o musicoterapeuta, ele já está estabelecendo um contato, o início de uma relação ou de uma possível relação. Então, os aspectos estéticos de beleza variam muito. Para nós, isso não é o mais importante, mas quando aparece é muito bom! A gente também não deve considerar que, pelo fato deles serem pessoas limitadas, deveríamos deixar as coisas acontecendo ou que não temos compromisso com eles. Temos sim. Nós temos compromisso no sentido de leválos a uma performance cada vez melhor dentro do que eles podem realizar.

GEIMT - Em alguma medida a Educação Musical poderia ser terapêutica e a Musicoterapia educativa?

Ana Sheila - Sim. Se você é um professor de Educação Musical, de instrumento, que é sensível, um bom pedagogo, domina a metodologia de ensino e é compreensivo com o aluno, essa prática educativa poderá ter "efeitos terapêuticos". Alguns alunos têm bloqueios emocionais, problemas para se comunicar e se relacionar, então a música e o domínio de um instrumento podem ter "efeitos terapêuticos", mas não se caracterizam como um processo terapêutico. Você pergunta se a Musicoterapia poderia ter efeito educativo. Sem dúvida, sabe por quê? Vamos pensar juntos: quando você coloca um CD e quer acompanhá-lo cantando, ou tocando um instrumento, você naturalmente obedece à música, à pulsação, ao ritmo; a música catalisa, chama você para 


\section{RBMT}

Revista Brasileira

de Musicoterapia

acompanhá-la. Falando da pessoa com deficiência, quando ela sente que está afinando junto com a música, conseguindo cantar alguma coisa, isso traz muito prazer e alegria para ela. No IPCEP ${ }^{13}$, onde eu trabalhei durante 40 e tantos anos, era muito interessante quando chegava um cliente novo. Eles chegavam à instituição com algumas habilidades, mas, depois que ingressavam na Musicoterapia e começavam a atuar e fazer os jogos, aparecia a repercussão deste trabalho com os outros professores de outras áreas. O psicólogo, 0 terapeuta ocupacional, o professor de alfabetização, diziam: "O paciente está tão melhor, ele está conseguindo fazer coisas que têm sido muito boas para ele! Vencendo dificuldades." Então a música é maravilhosa porque trabalha o cérebro, a cognição, afeta uma série de funções que são muito importantes para eles e você trabalha todas essas funções de uma maneira prazerosa, lúdica e que promove bem-estar. Eles amam, adoram! Quando eu chegava no IPCEP era uma gritaria, porque eles geralmente estavam no recreio e diziam: "Chegou a Sheila, chegou a Sheila!" Mas não é a "Sheila" que chegou, chegou a música. Você está proporcionando este prazer para eles, ou seja, um espaço de liberdade.

Eu acho que ambas as coisas têm vez. Muitas vezes a Educação Musical pode, de certa forma muito superficial, ter efeitos terapêuticos, fazer bem para a pessoa, enquanto a Musicoterapia, por sua vez, realmente tem efeitos educativos bem visíveis, comprovados e mensuráveis. Você tem avaliações, percebe, vai anotando, há uma série de instrumentos de avaliação sobre como as pessoas com deficiências vão reagindo ao longo do tempo e vencendo dificuldades.

GEIMT - É necessário alertar aos pais, responsáveis e às próprias pessoas com deficiência intelectual que têm aulas de música que, apesar de a Educação Musical ter eventuais efeitos terapêuticos, esta não é Musicoterapia?

\footnotetext{
${ }^{13}$ O Instituto de Psicologia Clínica Educacional e Profissional (IPCEP) foi fundado em 1958, na cidade do Rio de Janeiro. O instituto atende pessoas com deficiência intelectual, oferecendo atividades de Artes, Teatro, Expressão Corporal, Educação Física Especializada e Natação, além de atendimentos nas áreas de Musicoterapia, Fonoaudiologia e Psicologia. Ver "Instituto de Psicologia Clínica Educacional e Profissional". Disponível em: <http://ipcep.org.br/novo/>. Acesso em 03/10/2020.
}

Revista Brasileira de Musicoterapia - Ano XXII n² 28 ANO 2020

MENESES, Bruna et al. Musicoterapia, deficiência intelectual e musicalização terapêutica: uma entrevista com Ana Sheila Tangarife

(p. $71-88)$ 


\section{RBMT}

Revista Brasileira

de Musicoterapia

Ana Sheila - Claro. Tem que ser muito bem esclarecido que, com a Musicoterapia, você não está ensinando música para eles. Lá na nossa Clínica Social $^{14}$, às vezes, algumas mães chegavam com certa ilusão de que aconteceriam coisas diferentes. Eu dizia: "Não, nós não vamos dar aula de música para ele". Havia muita fantasia por parte dessas mães, o que a gente até compreende. Que a sala de Musicoterapia era um lugar mágico onde aconteceriam coisas inesperadas - e acontecem sim, mas nem sempre como as mães estão pensando. Quando elas se conscientizam do tipo de trabalho que está sendo feito é maravilhoso, aí tudo funciona muito bem e há total apoio das famílias.

GEIMT - Temos conhecimento de que a inclusão é um tema que vem sendo cada vez mais discutido por diversas áreas, como, por exemplo, a Educação, mas que nem sempre tal inclusão é efetivada de fato. $E$ quanto à Musicoterapia, como ela ocorre?

Ana Sheila - Entendi. Agora, tem que ver bem como é feita essa inclusão, porque, por exemplo, eu tive ex-alunos que trabalham em escolas do governo, grandes escolas e, para a minha surpresa, o espaço físico era um terreno imenso: havia o prédio onde estavam as crianças sem deficiências e havia o outro prédio, no mesmo espaço físico, mas só para as pessoas com deficiências. Então não havia inclusão. Para mim era uma inclusão perversa, porque eles estavam, geograficamente, no mesmo lugar, mas não estavam juntos. E aí eu digo uma coisa para vocês: quando você faz música, uma atividade musical, organiza uma banda ou um grupo para tocar, a música tem o poder de nivelar as crianças, mesmo aquelas que têm mais possibilidades. Há muitas crianças que não têm deficiência alguma, mas não têm o ritmo regular enão são muito musicais. Então é muito importante você juntá-las nessas atividades. A música permite que isso

\footnotetext{
${ }^{14}$ A Clínica Social Ronaldo Milleco é um núcleo de extensão do Centro Universitário do CBM, cujo propósito é oferecer atendimentos à comunidade nos mais variados quadros clínicos, além de oportunizar o exercício da Musicoterapia aos alunos dos cursos de Graduação e Pós- Graduação.

Revista Brasileira de Musicoterapia - Ano XXII n² 28 ANO 2020

MENESES, Bruna et al. Musicoterapia, deficiência intelectual e musicalização terapêutica: uma entrevista com Ana Sheila Tangarife
}

(p. $71-88)$ 


\section{RBMT}

Revista Brasileira

de Musicoterapia

seja feito. Muitas vezes na escolarização, na alfabetização isso é diferente, mas eu acho importante que na música todas as experiências entre crianças com e sem deficiência sejam feitas em conjunto, pois isso seria muito bom. A inclusão deve ser feita, mas tem que ver como ela está sendo feita e como os musicoterapeutas estão trabalhando para isso.

GEIMT - Então, nesse caso a Musicoterapia não tinha a inclusão como elemento intrínseco?

Ana Sheila - Não. Eu não sei atualmente, sabe por quê? Porque eu nunca vi e não tive nenhum aluno de Musicoterapia que fosse educador musical e que trabalhasse com inclusão. Então isso ficou um pouco longe, eu não ouço falar. Quem foi fazer Musicoterapia não trabalhava inclusão emEducação Musical, porque isso é uma coisa mais ou menos nova. A inclusão começou mais na parte acadêmica, de alfabetização e não com musicoterapeutas. Sempre houve professores de música nas escolas públicas, mas musicoterapeutas não havia.

GEIMT - Como a Musicoterapia pode ser utilizada com pacientes com deficiência intelectual severa?

Ana Sheila - Eu posso dar um exemplo para vocês de um caso emblemático que atendi, que me marcou muito. $\mathrm{Na}$ Pestalozzi ${ }^{15}$ havia um rapazinho que devia ter uns 13 ou 14 anos. Ele tinha microcefalia, um quadro severíssimo, não falava nada, não olhava para ninguém, tinha um quadro de autismo de isolamento total e só ficava nos corredores da instituição correndo de um lado para o outro, andando rapidinho e fazendo um som estranho. Ele ficava para lá e para cá. As pessoas passavam e ele não olhava, elas não lhe davam atenção e eu nunca consegui levá-lo para sala de Musicoterapia porque ele ignorava todo mundo. Um dia pensei: "Eu tenho que ver o que está acontecendo

\footnotetext{
${ }^{15}$ A Sociedade Pestalozzi do Brasil (SPB/Brasil) é uma associação sem fins lucrativos, de âmbito nacional, que promove o estudo, assistência, tratamento, educação e socialização de crianças e adolescentes com deficiência que necessitem de assistência terapêutica e pedagógica.

Revista Brasileira de Musicoterapia - Ano XXII n² 28 ANO 2020

MENESES, Bruna et al. Musicoterapia, deficiência intelectual e musicalização terapêutica: uma entrevista com Ana Sheila Tangarife
}

(p. 71 - 88) 


\section{RBMT}

Revista Brasileira

de Musicoterapia

com esse menino. Preciso que ele me descubra, ele tem que descobrir que existo! Como vou fazer para ele saber que existo?" Fiquei imóvel, encostada numa parede no meio do corredor e, quando ele passava por mim, eu reproduzia exatamente o som que ele estava fazendo, na mesma altura e timbre. Ele ia para lá e para cá até que começou a olhar esperando que eu fizesse o mesmo som. Nesse momento, ele começou a ver que eu existia e a partir disso deixei de ser uma pessoa estranha. Então pedi para a psicóloga dele e o inspetor que me ajudassem a levá-lo para minha sala, pois ele era excessivamente agressivo e batia em quem se aproximava. O inspetor me perguntou: "Você vai ficar sozinha com ele?" e eu respondi: "Sim, vou ficar. Pode deixá-lo aqui comigo". Era uma sala grande, ele se sentou no canto e eu no chão de frente para ele, bem distante, uns quatro metros. Ele ficou lá, não olhava para mim. Então pensei: "Como é que eu vou trabalhar com esse rapaz? Eu vou ter que esperar ele se manifestar de alguma forma". Aí ele começou a fazer um som que lembrava um porco. [Ana Sheila imita o som.] Ele continuava usando uma linguagem não verbal, mas era uma linguagem dele, então eu entrei nesse idioma e comecei a fazer também. Tudo o que ele fazia eu repetia. Depois comecei a introduzir novos vocábulos desse idioma. Então ele começou a rir, achou muito engraçado e com isso nós começamos a estabelecer um diálogo, um relacionamento. Assim, fui me aproximando dele aos pouquinhos. Andando rápido no processo, em certo momento já consegui pegar dois tamborzinhos pequenos, um para mim e outro para ele pegar ounão, e começamos a trabalhar. Ao final de 11 meses ele já estava num grupo pequeno de pessoas com necessidades muito parecidas e já sentado na cadeira dele, participando. Para mim esse caso foi um grande desafio.

Outro caso que tive foi de um rapaz com uma síndrome rara, a Síndrome de Rubinstein-Taybi. Ele não conseguia andar, mas se arrastava com o auxílio do andador; falava de maneira compreensível, mas era bastante complicadopor conta da síndrome raríssima. Tinha as mãos sem os polegares, aliás o polegar dele era curtinho, não tinha a falange final e apesar de se expressar, era muito contido por causa de todos esses problemas. Através das sessões de Musicoterapia ele foi adquirindo força e autoconfiança, foi se estruturando e, aos

Revista Brasileira de Musicoterapia - Ano XXII n² 28 ANO 2020

MENESES, Bruna et al. Musicoterapia, deficiência intelectual e musicalização terapêutica: uma entrevista com Ana Sheila Tangarife

(p. $71-88)$ 


\section{RBMT}

Revista Brasileira

de Musicoterapia

poucos, começou a se levantar da cadeira com o andador na frente dele. Começou a participar dos movimentos, das marchas, dos balanceios e com 0 tempo deixou o andador de lado, participando plenamente.

Um dia eu perguntei ao grupo: "Alguém gostaria de aprender a tocar flauta-doce?" - o que, neste caso, seria em outro grupo. Três pessoas se apresentaram e eu decidi fazer um grupinho de flauta-doce. O rapaz em questão ouviu falar, porque ele compreendia e se expressava bem, tinha uma cognição preservada e disse que queria participar. Eu fiquei sem saber o que fazer. Alguém aqui toca flauta-doce? Ela tem um buraco atrás, não tem? [Ana Sheila se dirige ao GEIMT] A flauta tem os furos superiores e um inferior, onde você encaixa o polegar. Mas ele não tinha o polegar normal. Eu fiquei desesperada! Iria começar a Musicalização Terapêutica com a flauta, mas não poderia dizer que ele não poderia participar. Não sabia o que falar e então pensei que ele mesmo iria perceber as dificuldades e perderia o interesse. Porém, ele não se desinteressou. Através do desejo dele de tocar, que era tão intenso, ele conseguiu arranjar uma posição na flauta em que a mão dele ficou parecida com uma "aranha" para poder vedar o furo inferior. Nesse grupo, que tinha cinco participantes, ele foi o melhor e o mais rápido a conseguir tocar. O desejo que ele tinha era tão grande e tão intenso que consegue tocar flauta- doce bem até hoje.

Este foi um caso muito interessante porque ele se desenvolveu através da Musicalização Terapêutica na flauta. Criei uma grafia para leitura das notas si, lá e sol descendentes e outra para a duração da nota. Colocava um traço abaixo do nome da nota e outro de outra cor com a duração dela. Por exemplo, se era uma semínima, era um tracinho; se era uma mínima, colocava um traço mais longo e; quando era uma semibreve, eu colocava uma linha bem longa, como se fossem quatro pedacinhos juntos. Com isso eles faziam leitura musical de uma grafia especial. Tocam até hoje com o Rafael em suas flautas. Por isso temos que acreditar que eles são capazes de fazer o que quiserem.

Apesar do autismo não ser considerado na área da deficiência intelectual, lembro-me de um autista de 14 anos (M.) que ficava se balançando de uma perna para a outra e dando uns gritos pavorosos, assustando até os vizinhos

Revista Brasileira de Musicoterapia - Ano XXII n² 28 ANO 2020

MENESES, Bruna et al. Musicoterapia, deficiência intelectual e musicalização terapêutica: uma entrevista com Ana Sheila Tangarife

(p. 71 - 88) 


\section{RBMT}

Revista Brasileira

de Musicoterapia

da instituição, que costumavam reclamar. Então eu pensei: "Ai meu Deus, preciso fazer alguma coisa com esse rapaz". Ele costumava ficar sozinho com a psicóloga e, então, um dia combinei com ela: "Você quer trazê- lo para minha sala? Quero tentar alguma coisa com ele". Havia na minha sala um tapete onde colocava os instrumentos e sentava no chão para trabalhar com os clientes. $A$ psicóloga veio com ele, mas ele não entrou; ela veio a segunda, a terceira vez, aí botei um bumbo deitado no meio da sala, no tapete. Um bumbo grande, que ficou virado para ele. Ele parou na porta e ficou olhando, então eu disse para psicóloga entrar com ele, sentar-se no tapete e ficar no bumbo junto a ele. Eu fiquei próxima da parede olhando para eles. Quando eles sentaram no tapete, ela disse: "Olha aqui, olha o instrumento...”.

Nas outras sessões eu comecei a me aproximar do tapete começando pela beiradinha enquanto ela estava ali. Quando já consegui me aproximar junto dele - ele do lado e eu do outro - a psicóloga passou a ficar no meu lugar, próxima à parede. A gente levou três meses para chegar até isso. Eu combinei com ela antes da sessão: "Tenta sair". Aí ela foi levantando, foi saindo... Quando levantou, ele se levantou também e saiu atrás dela. Na outra sessão fizemos tudo novamente aos pouquinhos. Ela conseguiu sair e ele ficou tão envolvido com o som do bumbo que nem percebeu a sua saída. Apesar disso, ele não deixava fechar a porta da sala e eu respeitei isso. Fomos trabalhando, trabalhando e era muito interessante que ele não olhava para mim. Ele arranhava a pele do bumbo e eu comecei a arranhar também e a fazer sons com a boca, mas ele continuava não olhando para mim. Então usei um artifício que funcionou muito: sabe esses pandeiros sem pele que só tem o aro? Peguei no aro do pandeiro, coloquei na frente do meu rosto, comecei a falar com ele e a fazer sons através do instrumento vazado. Ele começou a olhar para mim e achar graça. Estabelecemos uma conexão muito interessante; eu batia aqui,ele respondia ali e assim evoluímos muito bem.

Nessa mesma época, eu atendia a um cliente antes do horário dele, com quem eu trabalhava com violão. Era um paciente com Síndrome de Down bastante problemático. Houve um dia em que esse paciente saiu depois do 


\section{RBMT}

Revista Brasileira

de Musicoterapia

horário e M. já estava para entrar. Não houve tempo de guardar o instrumento no armário, apenas encostei o violão sobre a parede, fora do tapete, mas longe da sua visão. Quando M. entrou, olhou tudo em volta, foi em direção ao violão bem lentamente, colocou a mão com todo o cuidado no braço do instrumento, pegou o violão, encostou-o na parede e saiu. Ele não aceitou a mudança de ambiente. Com essa experiência, aprendi que quando a gente trabalha com autismo severo não podemos modificar o espaço sem eles estarem preparados. Ele levou dois meses para voltar. Retornamos todo trabalho novamente, mas como a mãe dele viajou, ele foi para outra instituição. Estes são exemplos de trabalhos que eu senti que funcionaram. De repente vocêsvão achar outras formas de trabalhar.

GEIMT - Professora, o que eu percebo é que nesta profissão devemos ter muito feeling, não é?

Ana Sheila - Exatamente. Vale tudo para você conseguir isso. E outra coisa, vocês não fiquem assustados, pois nós não temos o "poder" de fazer "muito mal" aos nossos clientes, fazer alguma coisa que possa prejudicá-los. Não fiquem assustados com isso. Na maioria das vezes a gente tem que ousar alguma coisa, alguma estratégia que vai se revelar muito boa. O máximo que pode acontecer é ele não se interessar por aquilo, mas mal não vai fazer. Feeling, empatia, percepção de onde você pode ir, entrando nos espaços que eles podem abrir para você, é só isso. Não tenham medo. A gente erra, eu já errei. Mas também acertamos.

GEIMT - Nessa relação terapêutica pode acontecer também de não ocorrer nenhuma reação visível do paciente, num primeiro momento. Porque nós, como educadores musicais, queremos que o aluno saia da primeira aula sabendo pelo menos um acorde. No caso da Musicoterapia, o paciente pode não manifestar nenhuma reação em princípio?

Ana Sheila - Sim, e outra coisa, se o paciente não estiver falando, você

Revista Brasileira de Musicoterapia - Ano XXII n² 28 ANO 2020

MENESES, Bruna et al. Musicoterapia, deficiência intelectual e musicalização terapêutica: uma entrevista com Ana Sheila Tangarife

(p. $71-88)$ 


\section{RBMT}

Revista Brasileira

de Musicoterapia

começa a cantar, a tocar seu instrumento e de vez em quando pergunta para ele:

"Oi, você está bem? Está gostando dessa música?" Vai falando com ele, usando seu feeling. Você tem que perceber o seu cliente, o que ele diz, e tem que perceber ainda mais quando se trata de uma pessoa autista. É preciso ter muita paciência e ver por onde você vai começar. Às vezes, uma abordagem pouco cuidadosa pode assustá-los e eles se fecham. O estímulo que usamos, o nosso objeto intermediário é a música, uma ponte extraordinária de relação.

GEIMT - Uma coisa que eu percebi a partir dos teus relatos, professora, é que a dificuldade de estabelecer a relação entre o paciente e o terapeuta, num primeiro momento, pode ser menor com aqueles que não têm deficiência intelectual severa. O primeiro passo para estabelecer esse vínculo com apessoa com deficiência intelectual severa seria "quebrar esse gelo", tentando se aproximar dela?

Ana Sheila - Sim e eles são ótimos de trabalhar quando se alcança isso. Agora, há uma questão: todos esses exemplos que dei foram de pacientes individuais, mas eu sempre trabalhei com grupo de pacientes no modelo de Grupo Operativo, de Pichón-Rivière. O Grupo Operativo é um grupo que se autogere, se auto-organiza, que decide, que tem os seus líderes democráticos, tem líder autocrático. No grupo, o musicoterapeuta tem papel de moderador, de facilitador, entendeu? Eu acredito muito no potencial do grupo, tanto que, em todos os meus casos individuais que ainda não tinham condição de estar emum grupo, quando eu percebia que tinham a mínima condição de ir para um, eu os levava. Logicamente, primeiro pergunto ao grupo se eles aceitam esse novo colega e ao paciente se ele quer ir para um grupo. Quando temos certaexperiência atendendo vários grupos, conseguimos conhecer os perfis deles, e quando eu tenho um cliente que já entendo bem e vejo que ele tem um perfil parecido com um dos grupos, eu já sei onde vou colocá-lo, e dá certo! Existem caminhos de agrupamento que vão variar segundo os critérios dos musicoterapeutas. Formar os grupos é uma arte, grupos que funcionem bem têm que ter, realmente, uma

Revista Brasileira de Musicoterapia - Ano XXII n² 28 ANO 2020

MENESES, Bruna et al. Musicoterapia, deficiência intelectual e musicalização terapêutica: uma entrevista com Ana Sheila Tangarife 


\section{RBMT}

Revista Brasileira

de Musicoterapia

série de itens, formas e avaliações.

GEIMT - Qual é a importância do envolvimento dos pais ou responsáveis no processo terapêutico do paciente com deficiência?

Ana Sheila - É importantíssimo. Fiz um grupo de pais, mães, irmãs, avós e famílias na Pestalozzi que foi fantástico! Trabalhei quinze anos com esse grupo. Foi a primeira experiência que tive de trabalho com família e marcou a minha vida. Eu até escrevi um artigo sobre isso há muitos anos ${ }^{16}$. Na Pestalozzi, trabalhei com uma mãe que tinha dois filhos adolescentes com Síndrome de Down: uma menina e um rapaz. Havia mais de duzentos aprendizes que almoçavam num pátio imenso, onde havia muita gente com bandejões. A mãe e seus filhos adolescentes chegavam para almoçar e permaneciam para o turno da tarde. Quando eles entravam, já iam derrubando os bandejões no chão e faziam o mesmo quando passavam nas mesas. Quando chegava essa mãe, arrastando aqueles dois filhos, era uma gritaria, uma coisa horrorosa. Quando chamei as mães, não apareceu ninguém. Aí eu chamei essa mãe, vendo a luta dela. "Você não gostaria de participar de um grupo de música, igual a dos seus filhos?". "Ai não, eu não dou para isso. Eu não sirvo. Não vai adiantar". Eu insisti: "Vamos lá, vamos lá, só para você ver o que é, para você ter uma ideia". Aí eu reuni duas mães e fomos juntas. Eu perguntei as músicas de que ela gostava e comecei a tocar. Depois de muita conversa, ela disse: "Não, eu não sou da música, eu sou da poesia". Eu respondi: "Não me diga, você é da poesia? Então você vai trazer uma para me mostrar". No outro encontro, ela trouxe uma poesia e começamos a fazer as sessões uma vez por semana. Era uma poesia que dizia assim: "Minha vida é uma história bem difícil de contar./ Eu me entrego na tristeza que o destino me traçou./ Essa vida tão amarga, eu procuro esquecer". Essa era a poesia dela. Vocês viram o peso? Terrível. Eu disse: "Muito bem, agora você vai botar música nessa poesia", e ela disse: "Ah, não, não sei, não vou" e começou a rir. A

\footnotetext{
${ }^{16}$ URICOECHEA, A. S. Musicoterapia e Deficiência mental: teorias e técnicas. Boletim, no 59-60, Sociedade Pestalozzi do Brasil, Rio de Janeiro, 1986.

Revista Brasileira de Musicoterapia - Ano XXII n² 28 ANO 2020

MENESES, Bruna et al. Musicoterapia, deficiência intelectual e musicalização terapêutica: uma entrevista com Ana Sheila Tangarife
}

(p. $71-88)$ 


\section{RBMT}

Revista Brasileira

de Musicoterapia

essa altura, o grupo já estava crescendo. Eu tinha um metalofone grande e um gravador, aí pedi a ela: "Você vai cantar. Fala: „Minha vida é uma história". "Não, não vou falar". "Fala". Aí ela falou: "Minha vida é uma história". Eu disse: "Repete: "Minha vida é uma história", „minha vida é uma história"”, e ela começou a rir. Continuei: "Vai. "„Minha vida é uma história". Canta agora: „Minha vida é uma história"'. E aí ela cantou a primeira frase musical. Essa mãe foi um dínamo dentro desse grupo. Ela vivia muito aborrecida com os filhos porque em casa eles ouviam música com volume muito alto e ela ficava comdor de cabeça, ainda mais porque o marido brigava com ela. Um dia ela começou a tocar tão forte o instrumento dela e ficou tão envolvida, que eu pedi ao grupo para diminuir o som. Sem ela perceber, o pessoal começou a parar de tocar e ela ficou sozinha batendo. Ela batia naquela marimba com uma força danada e quando descobriu que estava tocando sozinha, ela se espantou, começou a rir e disse: "Gente! Eu estava tocando muito alto, não é?" Aí nós morremos de rir e todos falamos: "Está vendo? Você não se queixa dos seus filhos? Olha aí. A gente entra na música, a gente é levado". Então houve uma mudança desse estranhamento dela com esses filhos. Foi maravilhoso. Elas começaram a fazer apresentações, o que foi fantástico.

GEIMT - O que é Musicalização Terapêutica e qual a diferença entre esta e a Musicoterapia?

Ana Sheila - Vou dar um exemplo para vocês de uma cliente que eu tive. Era uma senhora com mais ou menos 60 anos, muito tímida e depressiva. Ela perdeu o marido e estava no meu grupo da terceira idade. Um dia ela falou para mim: "Sheila, eu queria tanto voltar a fazer alguma coisa ao piano, eu já toquei, eu já estudei..." Eu respondi: "Então você vai ter que fazer isso individualmente, não vou poder fazer isso no grupo" - o grupo era de doze pessoas, a gente cantava e tocava. Ela começou a vir sozinha, trazia o Hanon, um método de piano, e tocava. Mas ia até um ponto e parava, não conseguia ir até o final da escala. Ela dizia: "Eu não consigo". "Mas você vai conseguir, não tem problema, 


\section{RBMT}

Revista Brasileira

de Musicoterapia

eu não estou preocupada se você consegue ou não, vamos tocar, vamos tocar".

De repente, ela resolveu me contar: "Eu tenho um piano muito bom na minha casa, mas eu não toco". Perguntei: "Mas por que não?". "Porque eu tenho uma vizinha que é maestrina na Escola Nacional de Música da UFRJ e eu não quero que ela me ouça tocando". Provavelmente, a maestrina nem sabia que essa senhora existia, mas ela continuava dizendo: "Não, eu não toco, uso o abafador quando quero tocar alguma coisa ao piano que é para ela não ouvir". Eu dizia: "Mas não tem problema, vamos continuar". Ou seja, a preocupação dela com uma pessoa que mora no outro andar, longe, mostra que seu bloqueio era muito intenso. Exercício para lá, exercício para cá, uma música para lá, outra para cá... E ela começou a recordar, mas não conseguia passar desses exercícios. Eu pensei: "Tem um bloqueio aí que eu preciso entender". Então ela me contou: "Meu pai era diretor e dono de um colégio onde eu e meus irmãos estudávamos e, quando tinha prova, ele ficava na banca junto com os nossos professores. Se a gente errasse, ele olhava paranós com muita raiva. Isso me marcou para o resto da vida e por isso eu não consigo tocar para ninguém que está me ouvindo, acho que vão fazer uma cara feia para mim". Eu disse: "Não faça isso, não pense assim, você vai conseguir". Então fomos conversando sobre isso, ela fazia os exercícios, contava mais coisas da vida dela, coisas relacionadas com o marido e tocávamos.

Para mim, a Musicalização Terapêutica é um pretexto e um contextopara fazer terapia. Ela não estava ali para aprender a tocar e nem ser concertista, vinha para resolver problemas. A parte da musicalização, dela voltar ao piano, era secundária, o principal para ela era trabalhar essas questões que estavam bloqueadas. Ela tirou o abafador do piano e saiu tocando, tocando forte, sem se importar com a vizinha maestrina e disse: "Não me importo se ela achar que toco mal, não me importo!". Então o fato dela vencer esses bloqueios foi o mais importante para mim. Eu vejo a Musicalização Terapêutica assim.

Tive um grupo de pesquisa com pessoas bipolares no Hospital psiquiátrico Nise da Silveira ${ }^{17}$. Essa pesquisa durou dois anos e depois eu os trouxe do

${ }^{17}$ O Instituto Municipal Nise da Silveira é um órgão da Secretaria Municipal de Saúde do Rio de Revista Brasileira de Musicoterapia - Ano XXII n² 28 ANO 2020

MENESES, Bruna et al. Musicoterapia, deficiência intelectual e musicalização terapêutica: uma entrevista com Ana Sheila Tangarife

(p. $71-88)$ 


\section{RBMT}

Revista Brasileira

de Musicoterapia

hospital psiquiátrico para serem atendidos na Clínica Social do Conservatório, pois eles tinham muita vontade de experimentar coisas novas. Durante este processo, eles demonstraram desejo de tocar violão. Havia três rapazes que queriam tocar violão e eu estava com dois estagiários que tocavam violão. Ambos montaram uma metodologia para dar aula, criando um método individualizado para cada um. Às vezes eles ficavam na posição de um acorde durante dois meses, porque treinavam a posição, paravam, falavam e conversavam. Tudo isso era um pretexto e um contexto para explorarem suas questões. Isso é o que eu chamo de Musicalização Terapêutica. Dar aula de instrumento (teclado, piano, flauta) é diferente. Eu não atendo uma pessoa só para que ela aprenda a tocar. Na Musicalização Terapêutica a pessoa para, conversa, expõe assuntos, a gente trabalha questões e eu peço para que eladê um exemplo ao piano daquilo que está sentindo, como ela expressaria isso no instrumento naquele momento. É completamente diferente e produz bons resultados.

Recebido em 09/12/2020 Aprovado em 06/02/2021

Janeiro. É uma instituição datada do século XX que vem orientada pelos preceitos da Reforma Psiquiátrica Brasileira, sendo que, no passado, foi o Centro Psiquiátrico Pedro II. A instituição oferece atendimentos voltados ao cuidado com a saúde mental de seus pacientes, incluindo uma rede de cuidados extra-hospitalares, transformando antigos espaços destinados às práticas manicomiais em projetos voltados para inclusão social através de atividades de cunho histórico, artístico, cultural e de formação. Ver "Instituto Municipal Nise da Silveira". Disponível em:<http://www.ccms.saude.gov.br/nisedasilveira/preservacao-memoria.php $>$. Acesso em 10/10/2020. 